\title{
Light chain deposition disease in kidney transplantation: a case report
}

\author{
Byung Chul Shin, Hyun Lee Kim, Jong Hoon Chung
}

Department of Internal Medicine-Nephrology, Chosun University Hospital, Gwangju, Korea

Background: The light chain deposition disease (LCDD) is a range from normal glomerular morphology to mesangioproliferative to mesangiocapillary to nodular sclerosing patterns. Due to the inconsistencies treatment and the poor graft outcome of LCDD, it is important to investigate for clinching this diagnosis.

Case report: A 53-year-old male was diagnosed end-stage renal disease due to chronic glomerulonephritis and underwent a live unrelated kidney transplantation in 20 years ago. Serum creatinine level gradually increased to $2.41 \mathrm{mg} / \mathrm{dL}$ and sub-nephrotic range proteinuria was observed. A kidney biopsy was performed, there are 9 glomeruli, which 3 glomeruli show global sclerosis and remain 6 glomeruli show segmental sclerosis with luminal hyalinosis and hyaline thickening of capillaries. There is no evidence of prominent tubulitis in non-atrophic tubules, vasculitis and capillaries.

Conclusions: Electron microscopic examination showed the characteristic intramembranous, subendothelial and paramesangial granular deposits and detached podocytes and diffuse effacement of foot processes $80 \%$. The spectrum of LCDD has a wide range of differential diagnosis and resulting in potential underdiagnosis.

Corresponding author: Byung Chul Shin

E-mail: bcshin@chosun.ac.kr

(c) The Korean Society for Transplantation

This is an Open Access article distributed under the terms of the Creative Commons Attribution Non-Commercial License (http://creativecommons.org/licenses/by-nc/4.0/) which permits unrestricted non-commercial use, distribution, and reproduction in any medium, provided the original work is properly cited. 